\title{
MELHORAMENTO DO TRIGO: XVI. COMPORTAMENTO DE NOVAS LINHAGENS EM DIFERENTES REGIÓES DO ESTADO DE SÃO PAULO (1)
}

\author{
CARLOS EDUARDO DE OLIVEIRA CAMARGO $\left({ }^{2,4}\right)$, JOÄO CARLOS FELÍCIO $\left({ }^{2,4}\right)$, \\ BENEDITO DE CAMARGO BARROS $\left({ }^{3,4}\right)$, ANTONIO WILSON PENTEADO \\ FERREIRA FILHO $\left({ }^{2}\right)$, JOSÉ GUILHERME DE FREITAS $\left({ }^{2}, 4\right)$, \\ JAIRO LOPES DE CASTRO $\left({ }^{2,4}\right)$ e JOSÉ CARLOS SABINO $\left({ }^{2,4}\right)$
}

\begin{abstract}
RESUMO
Vinte e duas linhagens de trigo foram comparadas com cultivares comerciais, em ensaios instalados em diferentes localidades paulistas em 1983, 1984 e 1985, analisando-se os parâmetros seguintes: rendimento de grāos, altura de plantas, ciclo em dias da emergência ao florescimento e da emergência à maturação, notas de acamamento, comprimento da espiga, número de gräos por espiga e por espigueta, número de espiguetas por espiga, peso de cem gräos, resistência aos agentes causais de oldio e doenças das folhas em condição de campo; resistência aos agentes causais das ferrugens do colmo e da folha em campo e em casa de vegetação. Em laboratório, foram realizados estudos da tolerância ao alumínio, em soluções
\end{abstract}

(1) Com recursos complementares do Acordo do Trigo entre as Cooperativas de Produtores Rurais do Vale do Paranapanema e a Secretaria de Agricultura e Abastecimento, por meio do Instiłuto Agronômico. Trabalho apresentado na XIV Reuniāo Nacional de Pesquisa de Trigo, Londrina (PR), julho de 1986. Recebido para publicação em 22 de agosto de 1986. nas (SP).

$\left({ }^{2}\right)$ Seção de Arroz e Cereais de Inverno, Instituto Agronómico (IAC), Caixa Postal 28, 13001 Campi-

(3) Seção de Doenças das Plantas Alimentícias Básicas e Olericolas, Instituto Biológico, Campinas (SP).

$\left({ }^{4}\right)$ Com bolsa de suplementação do CNPq. 


\begin{abstract}
i
nutritivas. Em relação à produção de grãos, deștacaram-se as linhagens IAC-103, IAC-104, IAC-107, IAC-167 e PAT 73121, que não diferiram dos cultivares controles (BH-1146, IAC-18 e Alondra $\mathrm{S}-46)$. As linhagens IAC-104, IAC-107, IAC-111, IAC-167, ISWYN-31/82 e Kenya Kifaru mostraram plantas de porte semi-anão. As linhagens IAC-108 e ISWYN-31/82 destacaram-se quanto à resistência ao agente causal de oídio; $\mid \mathrm{AC}-110 \mathrm{e}$ $\mid A C-111$, quanto à menor ocorrência de doenças nas folhas; $\mid A C-100$, IAC-101, IAC-111, IAC-167 e PAT 73121, quanto à resistência ao agente causal da ferrugem-da-folha em condição de campo; IAC-104, IAC-108, IAC-110, IAC-111, IAC-167, ISWYN-31/82 e Kenya Kifaru, quanto à resistência ao agente causal da ferrugem-do-colmo, em campo. A linhagem IAC-167 e o cultivar Alondra S-46 foram resistentes a oito raças de Fuccinia graminis tritici, agente da ferrugem-do-colmo, em casa de vegetação, e IAC-103 e Kenya Kifaru foram resistentes a sete raças. A IAC-167 foi resistente a três raças de Puccinia recondita, agente da ferrugem-da-folha, em casa de vegetação. As linhagens IAC-99 e IAC-109 foram tão tolerantes à toxicidade de aluminio quanto os cultivares $\mathrm{BH}-1146$ e $\mathrm{ACC}-18$, sendo IAC-100, IAC-106, IAC-167 e ISWYN-31/82, as mais sensiveis.
\end{abstract}

Termos de indexação: trigo, cultivares, linhagens, produtividade, resistência, ferrugens, alumínio, porte semi-anão.

\title{
1. INTRODUÇÃO
}

A cultura do trigo é uma das poucas opções durante o período março-setembro em sucessão às culturas tradicionalmente plantadas no verão, visando ao melhor aproveitamento das áreas agricultáveis e maior lucro aos agricultores do Estado de São Paulo. A triticultura paulista, até o inicio da década de 80 , instalava-se, em sua maior parte, no Vale do Paranapanema e no Sul, onde o trigo é plantado em sucessão à soja. Nessas regiōes, sua cultura é feita em condiçōes de sequeiro, em virtude da relativa disponibilidade de água para suprir a demanda das plantas. A partir de 1980, com o estabelecimento da cultura irrigada por aspersão, praticamente em todo o Estado é possivel o cultivo com trigo, pois a deficiência hídrica no inverno pode ser facilmente eliminada por essa prática. Faz exceção a região litorânea, pelo excesso de umidade relativa e altas temperaturas, condiçōes desfavoráveis à triticultura e altamente favoráveis à ocorrência de doenças.

O programa de obtenção de novos cultivares de trigo do Instituto Agronômico, com a colaboração do Instituto Biológico, tem por objetivo, através de cruzamentos, seguidos de vários ciclos de seleção, obter tinhagens portadoras das seguintes caracteristicas: (a) boa perfilhação útil; alto número de espigas por planta; espigas grandes e densas; grãos grandes e de bom peso hectolitrico; 
espiguetas com maior número de flores férteis; ciclo da emergência à maturação de 100 a 120 dias, favorecendo a rotação com outras culturas (além disso, o trigo, permanecendo no terreno por menor espaço de tempo, fica menos sujeito às irregularidades climáticas); porte baixo; resistência à degrana e ao acamamento, e alta capacidade de adaptação geográfica; (b) para o Estado de São Paulo, os cultivares necessariamente precisam mostrar resistência aos agentes causais das ferrugens-do-colmo e da-folha, as doenças de maior importância para o nosso meio; além disso, seria interessante que apresentassem resistência a Helminthosporium sativum Pammel, King \& Bakke, Septoria nodorum Berk, Gibberela zeae (Schw) Petch e Erysiphe graminis tritici Em. Marchal; (c) tolerância à toxicidade de aluminio.

O cultivar IAC-5 foi distribuído aos agricultores no fim da década de 60 . Apesar do porte relativamente alto, apresentava nessa ocasiāo boa resistência de campo aos agentes causais das ferrugens do colmo e da folha, boa adaptação às condiçōes de baixa fertilidade do solo, precocidade e boa produçāo (CAMARGO, 1972, e CAMARGO et al., 1974). Em meados da década de 70, foram lançados comerciaimente para o Estado de São Paulo os cultivares IAC-17 e IAC-18, que, confrontados com o 'BH-1146 e. 'IAC-5', em experimentos conduzidos no periodo 1976-80, nas regiōes tritícolas paulistas, demonstraram grande infecção do fungo Puccinia graminis tritici (ferrugem-do-colmo), embora inferiores às registradas pelas testemunhas. O 'IAC-18' apresentou, nesse período, uma produção de grãos 10 e $14 \%$ superior, respectivamente, aos cultivares $\mathrm{BH}-1146$ e IAC-5 (FELICIO et al., 1983).

No inicio de 1980, foram recomendados para plantio no Estado de São Paulo os cultivares IAC-21 e IAC-22. Em comparação com as testemunhas, 'BH-1146' e 'IAC-5', o 'IAC-21' mostrou produção de grãos 8 e 12\% superior, e 'IAC-22', 5 e 14\% respectivamente. Esses cultivares apresentaram, ao longo de cinco anos de estudo, menores índices de infecção de ferrugem-do-colmo, sobressaindo o 'IAC-22', com baixissimos indices de infecção deste patógeno. Ambos mostraram reação de tolerância à toxicidade de alumínio (FELíClO et al., 1985).

Os cultivares IAC-24, IAC-25, IAC-29 e IAC-60 foram os primeiros obtidos no programa de melhoramento genético do Instituto Agronômico por meio de cruzamentos seguidos de vărios ciclos de seleção, portadores de alta produtividade e porte semi-anão, a partir da fonte de nanismo Norin-10 x Brevor 14. 'IAC-24' e ' $\mid A C-60$ ' são tão tolerantes à toxicidade de $\left.A\right|^{3+}$ quanto ' $B H-1146$ ' e ' $\mid A C-5$ ', de porte alto (CAMARGO et al., 1985a; CAMARGO et al., 1987b e CAMARGO et al., 1985b). Esses cultivares são indicados para plantio nas regiōes onde a irrigação por aspersão é utilizada, permitindo alto potencial de produção com adubação nitrogenada devido à acentuada resistência ao acamamento.

Neste trabalho, procurou-se estudar vinte e duas novas linhagens, obtidas pelo instituto Agronômico, com o objetivo de identificar as mais promissoras. 


\section{MATERIAL E MÉTODOS}

\subsection{Origem das linhagens estudadas}

As linhagens estudadas săo originárias de seleções nas populaçōes segregantes de cruzamentos realizados no Instituto Agronômico ou de introduções de diversas procedências.

IAC-97, IAC-112 e IAC-113 - Selecionadas a partir do híbrido 1032, obtido do cruzamento entre a linhagem Pel 10054-65, introduzida do Instituto de Pesquisa e Experimentação Agropecuária do Sul (IPEAS), Pelotas, RS, e IRN299-66, proveniente do International Spring Wheat Rust Nursery (IRN), referente ao ano de 1966, conduzido pelo Instituto Biológico.

IAC-98, IAC-102 e IAC-107 - Obtidas por seleções do híbrido 1031, obtido do cruzamento entre a linhagem IRN-641-70 e o cultivar BH-1146.

IAC-99 - Oriunda da seleção do híbrido 1003, originada do cruzamento entre a linhagem Pel 4178-67, introduzida do IPEAS, e o 'S-12', selecionado pela Secretaria da Agricultura do Estado do Rio Grande do Sul.

IAC-100 - Introduzida, em 1980, da Universidade Estadual de Oregon, Corvallis, EUA, é originária de seleção do cruzamento entre o híbrido (Bezostaja $x$ $x$ Correcaminos) $x$ INIA-66 e o cultivar mexicano Calidad. Bezostaja é um cultivar russo e Correcaminos e INIA-66 foram obtidos no México.

IAC-101 - Selecionada a partir do híbrido 907, oriundo do cruzamento entre a linhagem P 29362, proveniente da Estação Experimental de Capão Bonito, e o 'IRN-526-63'.

IAC-103 - Selecionada a partir do cruzamento entre os híbridos CIANO$-67^{2}$ x (Lerma Rojo-64 x Sonora-64) e Tobari“"S" x 8156R, de origem mexicana.

IAC-104 - Oriunda de seleção do híbrido 885, proveniente do cruzamento entre a linhagem IRN-484-70 e o ' $\mathrm{BH}-1146$ '.

IAC-105 - Introduzida, em 1980, da Universidade Estadual de Oregon, Corvallis, é originária de seleção do hibrido entre o cultivar Kavkaz, de origem russa, e o mexicano 'Gavilan'.

IAC-106 - Selecionada a partir do híbrido 557, proveniente do cruzamento envolvendo o hibrido entre o cultivar mexicano Sonora-64 e o ' $\mathrm{BH}-1146$ ', seguido de um retrocruzamento para o $\mathrm{BH}-1146$, e o híbrido entre o cultivar mexicano Ciano-67 e o 'BH-1146', seguido de dois retrocruzamentos para este último.

IAC-108 - Oriunda da seleção do híbrido 814, originado do cruzamento entre a linhagem IRN-514-70 e o 'IAS-51', introduzido do IPEAS, Pelotas.

IAC-109 - Obtida por seleção do híbrido 257, resultante do cruzamento entre 0 'Sonora-64', de origem mexicana, e o 'IAC-5'. 
IAC-110 - Selecionada a partir do hibrido 1002, obtido do cruzamento entre o 'IAC-5 e a linhagem IRN-76-70.

IAC-111 - Introduzida da Universidade Estadual de Oregon, Corvallis, é originária de seleção do híbrido entre o 'S-148', de origem desconhecida, e o 'Bolillo, de origem mexicana.

IAC-167 - Introduzida do Centro Internacional de Melhoramento de Milho e Trigo (CIMMYT), México, através do Ensaio Internacional de Rendimento de Trigos de Primavera (ISWYN), plantado em 1982 no Centro Experimental de Campinas. Ė originário de seleção de material proveniente de Novi Sad, localidade da lugoslávia.

PAT-73121 - Introduzida, através do CIMMYT, México, em 1982, foi selecionada no Centro de Pesquisas da FECOTRIGO, Cruz Alta, RS.

ISWYN-31-82 - Introduzida do CIMMYT, em 1982, é originária de seleçāo do híbrido HD 2236, proveniente da İndia.

ISWYN-35-82 - Introduzida do CIMMYT, em 1982, é proveniente do hibrido QT 4083, de origem norte-americana. Quênia.

Kenya Kifaru - Introduzida do CIMMYT, em 1982, proveniente do

Como controle, foram utilizados os seguintes cultivares: $\mathrm{BH}-1146$, IAC-18 e Alondra S-46, cujas caracteristicas agronômicas e origem foram descritas por CAMARGO et al. (1985b).

\subsection{Ensaios de campo conduzidos em diferentes locais paulistas}

Três experimentos foram instalados em 1983 nos seguintes locais: Estação Experimental de Capão Bonito, Centro Experimental de Campinas e Fazenda Santa Inês, em Macaraí. Em 1984 e 1985, foram instalados, respectivamente, na Estação Experimental de Tietê e no Centro Experimental de Campinas.

Em cada experimento, composto de 75 parcelas, foi utilizado o delineamento estatístico de blocos ao acaso, com três repetições. Cada parcela foi constituída de cinco linhas de $3 \mathrm{~m}$ de comprimento, espaçadas de $0,20 \mathrm{~m}$, deixando-se uma separação lateral de $0,60 \mathrm{~m}$ entre as parcelas. A semeadura foi na base de 80 sementes viáveis por metro de sulco, equivalendo a 1.200 por parcela, com uma área útil de $3,0 \mathrm{~m}^{2}$.

$\mathrm{Na}$ instalação dos ensaios, retiraram-se amostras compostas dos solos dos locais estudados, cujos resultados analíticos $\left({ }^{5}\right)$ foram os seguintes:

$\left({ }^{5}\right)$ Análise efetuada pela Seção de Fertilidade do Solo e Nutrição de Plantas, Instituto Agronômico. 


\begin{tabular}{|c|c|c|c|c|c|}
\hline Determinaçōes & \multirow{2}{*}{$\begin{array}{c}\text { Capāo Bonito } \\
1983\end{array}$} & \multirow{2}{*}{$\begin{array}{c}\text { Maracaí } \\
1983\end{array}$} & \multirow{2}{*}{$\begin{array}{l}\text { Tietê } \\
1984\end{array}$} & \multicolumn{2}{|c|}{ Campinas } \\
\hline & & & & 1983 & 1985 \\
\hline$P$ resina $\left(\mu \mathrm{g} / \mathrm{cm}^{3}\right)$ & 17 & 33 & 43 & 41 & 33 \\
\hline M.O. (\%) & 3,6 & 3,9 & 3,0 & 3,3 & 3,9 \\
\hline $\mathrm{pH}\left(\mathrm{CaCl}_{2}\right)$ & 4,5 & 4,8 & 5,3 & 5,1 & 5,0 \\
\hline $\mathrm{K}\left(\mathrm{meq} / 100 \mathrm{~cm}^{3}\right)$ & 0,10 & 0,35 & 0,60 & 0,19 & 0,27 \\
\hline $\mathrm{Ca}$ & 2,6 & 3,1 & 5,3 & 3,3 & 2,3 \\
\hline $\mathrm{Mg}$ & 0,5 & 1,2 & 1,3 & 1,3 & 0,8 \\
\hline $\mathrm{H}+\mathrm{Al} "$ & 6,8 & 4,3 & 2,3 & 3,3 & 4,0 \\
\hline S & 3,2 & 4,7 & 7,2 & 4,8 & 3,4 \\
\hline $\mathrm{T}$ & 10,0 & 9,0 & 9,5 & 8,1 & 7,4 \\
\hline$V(\%)$ & 32 & 52 & 76 & 59 & 46 \\
\hline
\end{tabular}

Utilizou-se da irrigação por aspersão nos ensaios conduzidos em Campinas, enquanto nas demais localidades eles não foram irrigados.

Para a avaliação da ferrugem-do-colmo e da-folha, de manchas foliares, causadas por Helminthosporium sp. e Septoria sp. e de oídio, seguiram-se as escalas e critérios citados por CAMARGO et al. (1987a).

Os dados relativos ao ciclo, da emergêricia ao florescimento e da emergência à maturação, ao acamamento, à altura das plantas, ao comprimento da espiga, ao número de espiguetas por espiga, grãos por espiga e por espigueta, ao peso de cem grãos e à produção de grāos, foram obtidos conforme metodologia descrita por CAMARGO et al. (1987a).

\subsection{Ensaios em condição de casa de vegetação e laboratório}

2.3.1 Resistência a raças dos agentes causais da ferrugem-do-colmo e da-folha

Amostras de sementes das linhagens e cultivares foram remetidas ao Centro Nacional de Pesquisa de Trigo da EMBRAPA, Passo Fundo (RS), para avaliação, quanto à resistência em estádio de plântula, em condições de casa de vegetação, a algumas raças de Puccinia graminis tritici (G-13, G-15, G-17, G-18, G-19, G-20, G-21 e G-22) e de Puccinia recondita (B-26, B-27 e B-29), de ocorrência comum no Brasil (BARCELLOS, 1985, e COELHO, 1985).

\subsubsection{Tolerância à toxicidade de aluminio}

As linhagens e cultivares foram testados para tolerância a 0, 2, 3, 6, 8 e $10 \mathrm{mg} /$ litro de $\mathrm{Al}^{3+}$ em soluções nutritivas, conforme método já publicado (CAMARGO \& OLIVEIRA, 1981; CAMARGO et al., 1980 e MOORE et al., 1976). 


\section{RESULTADOS E DISCUSSÃO}

As produções médias de grãos, transformadas em quilograma/hectare, das linhagens e cultivares de trigo estudados em 1983, 1984 e 1985, em diferentes regiōes do Estado de São Paulo, encontram-se no quadro 1. Os resultados da análise estatística dos cinco experimentos, analisados separadamente, mostraram efeitos altamente significativos para linhagens e cultivares.

Através do teste de Tukey aplicado ao nivel de $5 \%$ para a comparação das médias nos tratamentos no ensaio instalado em Capăo Bonito, em 1983, verificou-se que apenas as linhagens IAC-99, IAC-106 e PAT-73121 diferiram significativamente dos cultivares controles, BH-1146, IAC-18 e Alondra-S-46.

No ensaio instalado em 1983, em Campinas, destacaram-se, quanto à produção de grãos, as linhagens IAC-99, IAC-104, IAC-111 e PAT-73121, que não diferiram dos cultivares $\mathrm{BH}-1146$ e IAC-18. Dessas linhagens, somente a PAT-73121, que produziu $2.554 \mathrm{~kg} / \mathrm{ha}$, diferiu estatisticamente do 'Alondra-S-46', com $1.262 \mathrm{~kg} / \mathrm{ha}$. No ensaio de Campinas, 1985, com irrigação por aspersão, as linhagens que apresentaram maior produção de grãos foram IAC-97, IAC-98, IAC-100, IAC-103, IAC-104, IAC-105, IAC-106, IAC-107 e IAC-108, porém nenhuma diferiu dos cultivares $\mathrm{BH}-1146$ e Alondra-S-46, e apenas IAC-100 foi significativamente superior ao 'IAC-18'.

No ensaio plantado em Maracaí, em 1983, destacou-se quanto à produção de grãos a linhagem IAG-98, que diferiu estatisticamente somente das linhagens menos produtivas: IAC-101, IAC-109, IAC-112, IAC-113, ISWYN 31/82 e ISWYN 35/82.

No ensaio de Tietê, 1984, a linhagem IAC-167, com $3.308 \mathrm{~kg} / \mathrm{ha}$, diferiu pelo teste de Tukey aplicado ao nivel de $5 \%$ de todas as linhagens e cultivares estudados.

Analisando em conjunto os cinco ensaios, verificaram-se efeitos altamente significativos para genótipo, ensaio e interação genótipo $\mathrm{x}$ ensaio. Pelo teste de Tukey, observou-se que IAC-97, IAC-100, IAC-103, IAC-104, IAC-107, IAC-167, PAT-73121, BH-1146 e IAC-18 foram os mais produtivos, porém somente diferiram da linhagem IAC-105, que foi a menos produtiva na média dos cinco experimentos em estudo.

Considerando os cinco experimentos, os graus máximos de infecção de oídio, de ferrugem-do-colmo e da-folha, bem como de outras moléstias foliares, encontram-se no quadro 2.

As linhagens IAC-104, IAC-108, IAC-110, IAC-111, IAC-167, ISWYN $31 / 82$ e o cultivar Alondra-S-46 mostraram-se resistentes à ferrugem-do-colmo em condições naturais de infecção, exibindo reações iguais ou inferiores a 5S. Nessa mesma situação, o 'BH-1146', suscetivel à ferrugem-do-colmo, exibiu um grau de infecção máximo, $30 \mathrm{~S}$. 


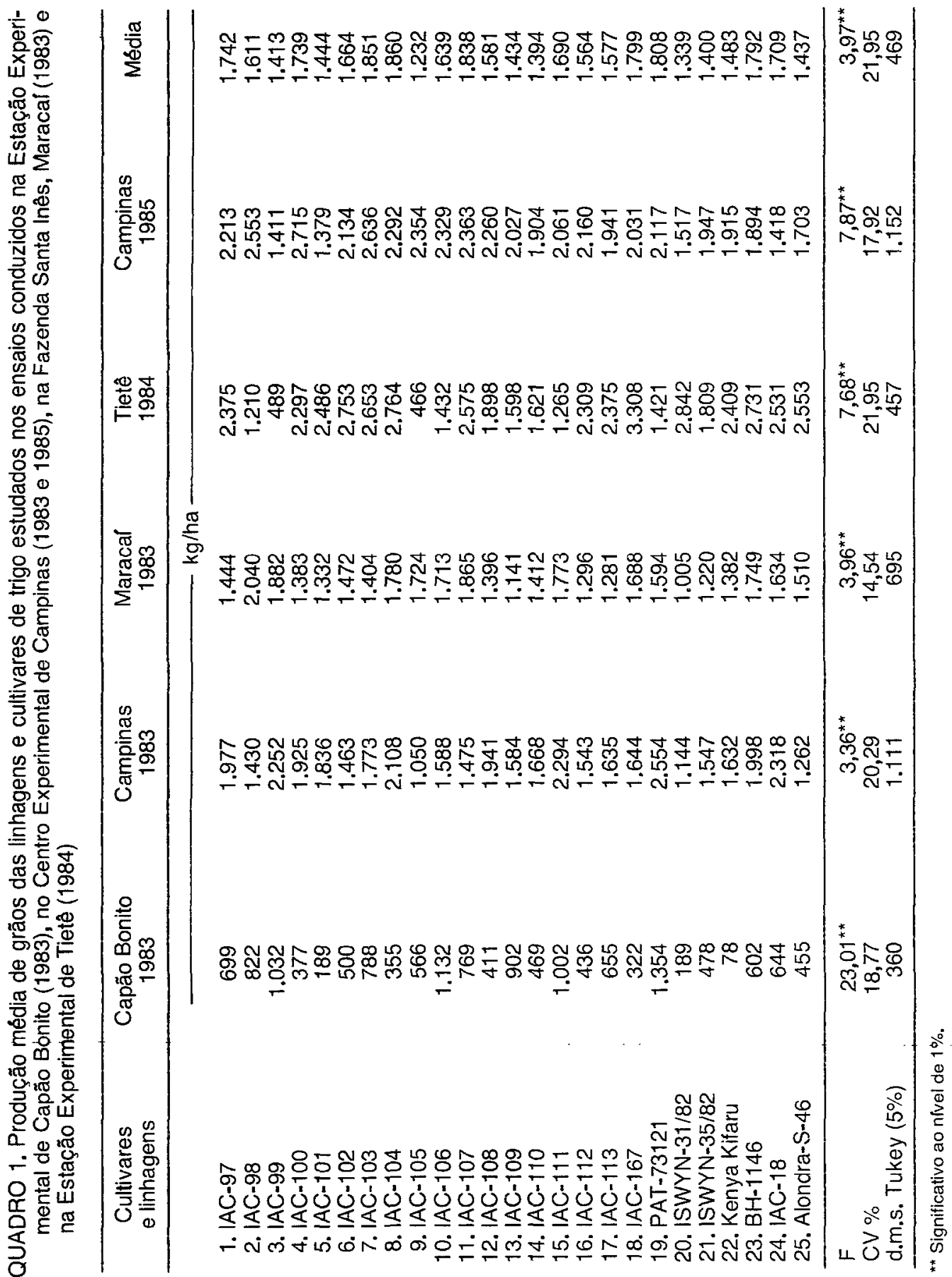




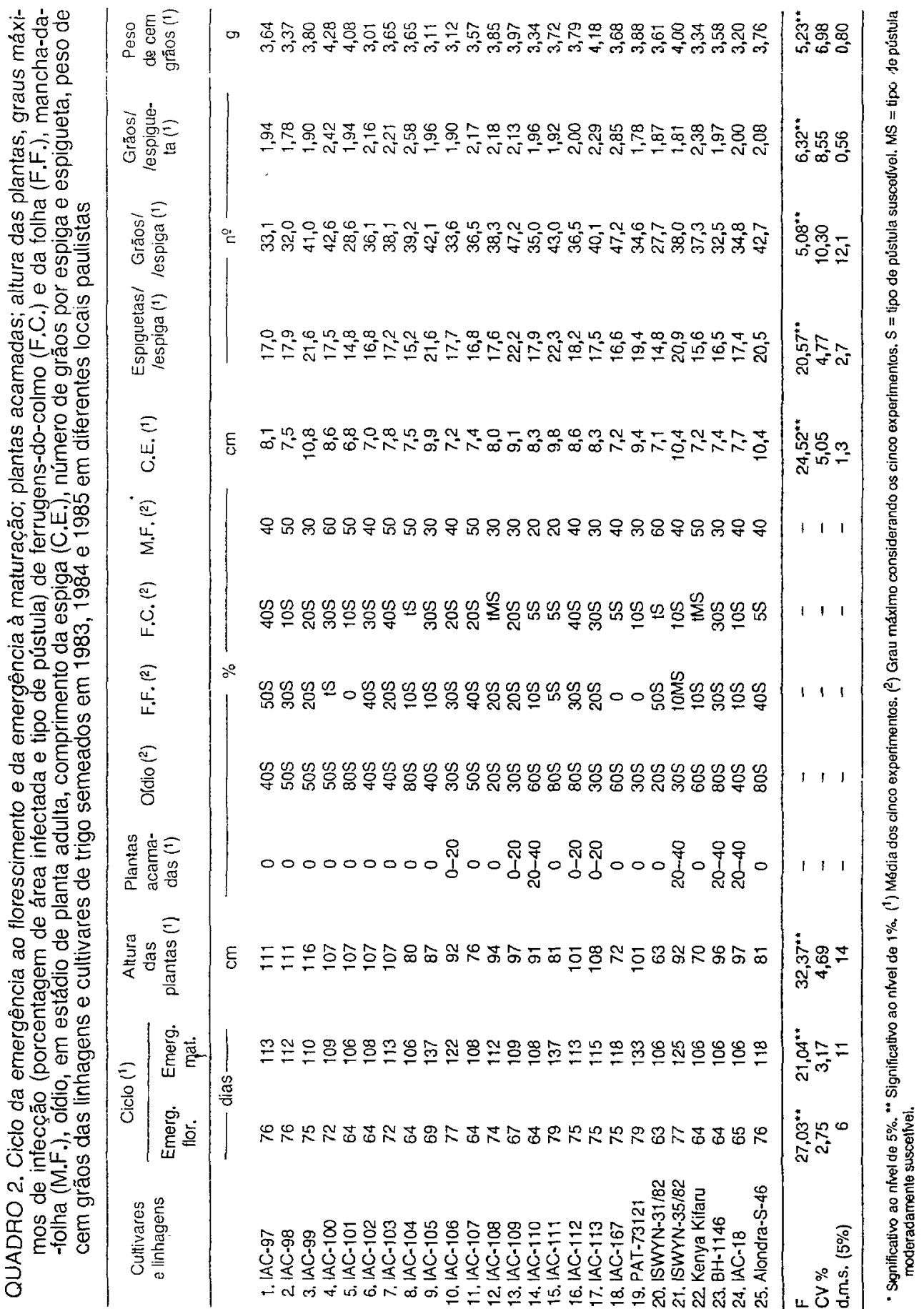


Em relação à ferrugem-da-folha, destacaram-se, quanto à resistência em planta adulta, as linhagens IAC-100, IAC-101, IAC-111, IAC-167 e PAT-73121, com graus de infecção iguais ou inferiores a $5 S$, ao passo que o 'Alondra-S-46' apresentou um grau máximo de infecção, $40 \mathrm{~S}$.

Quanto à resistência ao oídio em planta adulta, as linhagens IAC-108 e ISWYN 31/82 foram as mais resistentes, com um grau de infecção de 20S, enquanto os cultivares $\mathrm{BH}-1146$ e Alondra $\mathrm{S}-46$ apresentaram $80 \mathrm{~S}$, como grau máximo.

A ocorrência de mancha nas folhas foi bastante acentuada no ensaio plantado em Capão Bonito em 1983, sendo suscetiveis praticamente todos os cultivares e linhagens. Destas, IAC-110 e IAC-11i foram as que mostraram menor intensidade de ataque.

As reaçōes no estádio de plântula a $P$. graminis f. sp., tritici e $P$. recondita, em casa de vegatação, encontram-se no quadro 3. A linhagem IAC-167 e o cultivar Alondra-S-46 foram resistentes às oito raças testadas do agente causal da ferrugem-do-colmo. IAC-103 e Kenya Kifaru mostraram-se resistentes a sete; IAC-98, IAC-106 e ISWYN 35/82, a seis, e IAC-97, IAC-104, IAC-108 e IAC-110, a cinco raças do agente causal da ferrugem-do-colmo. A linhagem IAC-167 mostrou-se resistente às três raças testadas de $P$. recondita, em casa de vegetação. Pela sua grande resistência às ferrugens-do-colmo e da-folha, em condição de campo e de casa de vegetação, ela será de grande valor no programa de melhoramento do trigo do Instituto Agronômico como fonte de resistência àquelas doenças.

Os cultivares comerciais $\mathrm{BH}-1146$ e IAC-18 foram suscetiveis às oito raças de ferrugem-do-colmo; $\mathrm{BH}-1146$ foi suscetivel às três raças testadas do agente causal da ferrugem-da-folha em casa de vegetação e IAC-18,a duas delas. Apesar da suscetibilidade desses cultivares a várias raças dos patógenos das ferrugens, verificou-se, em condição de campo, nos anos considerados, que o grau máximo de infecção não ultrapassou $40 \mathrm{~S}$ para ferrugem-do-colmo e $50 \mathrm{~S}$ para ferrugem-da-folha, o que provavelmente tenha decorrido de condições não favoráveis ao desenvolvimento dos fungos ou de sua incidência tardia.

O ciclo em dias da emergência ao florescimento e da emergência à maturação, a porcentagem de plantas acamadas, a altura da planta, o comprimento da espiga, o número de grãos por espiga e por espigueta, o número de espiguetas e o peso de cem grãos das linhagens e cultivares estudados, considerando a média dos cinco ensaios, encontram-se no quadro 2.

Quanto ao ciclo, as linhagens IAC-105, IAC-111 e PAT-73121 demonstraram-se tardias; as linhagens IAC-106 e IAC-167, de ciclo médio, semelhante ao cultivar Alondra-S-46, e as demais linhagens foram tão precoces quanto os cultivares comerciais $\mathrm{BH}-1146$ e IAC- 18 . 





No que se refere à altura das plantas, as linhagens IAC-104, IAC-107, IAC-111, IAC-167 e ISWYN-31/82 e o 'Alondra-S-46' mostraram-se significativamente mais baixas que as dos cultivares $\mathrm{BH}-1146$ e IAC-18. Considerando que esses germoplasmas também não exibiram plantas acamadas, estariam, portanto, entre aqueles com potencial de cultivo em condições de irrigação. As linhagens IAC-106, IAC-109, IAC-110, IAC-112, IAC-113 e ISWYN-35/82 e os cultivares $\mathrm{BH}-1146$ e IAC-18 apresentaram-se sensiveis ao acamamento, que foi associado a um porte de planta de médio para alto. Tais germoplasmas năo seriam indicados para condiçōes irrigadas, pois suas produçōes poderiam ser prejudicadas pelo acamamento, quando em condições de colheita mecânica.

A linhagem IAC-99 foi a que mostrou espigas mais compridas, diferindo estatisticamente das demais linhagens e cultivares, com exceção do IAC-105, IAC-111, ISWYN-35/82 e Alondra-S-46. A linhagem IAC-111 demonstrou o maior número de espiguetas por espiga, não diferindo das linhagens IAC-99, IAC-105, IAC-109, ISWYN-35/82 e do cultivar Alondra-S-46. As linhagens IAC-109 e IAC-167 apresentaram o maior número de grãos por espiga, não diferindo das linhagens IAC-99, IAC-100, IAC-102, IAC-103, IAC-104, IAC-105, IAC-107, IAC-108, IAC-111, IAC-112, IAC-113, ISWYN-35/82 e Kenya Kifaru e do. 'Alondra-S-46'. A linhagem IAC-167 exibiu espigas com maior fertilidade, isto é, com maior número de grãos por espigueta, diferindo estatisticamente de todos os germoplasmas, com exceção das linhagens IAC-100, IAC-104, IAC-113 e Kenya Kifaru. A linhagem IAC-100 mostrou os grãos mais pesados, diferindo porém, estatisticamente, apenas das linhagens IAC-98, IAC-102, IAC-105, IAC-106, IAC-110 e Kenya Kifaru e do 'IAC-18'.

O comprimento médio das raízes das 25 linhagens e cultivares de trigo, medido após 72 horas de crescimento nas soluções nutritivas completas, seguidos de 48 horas de crescimento nas soluçōes de tratamento contendo seis diferentes concentrações de alumínio, encontram-se no quadro 4.

Considerando $2 \mathrm{mg} /$ litro de $\mathrm{Al}^{3+}$, pode-se verificar que as linhagens IAC-100, IAC-106, IAC-167 e ISWYN-31/82 foram sensiveis a essa concentração, $\mathrm{e}$ as demais, tolerantes.

A linhagem ISWYN-35/82 e o cultivar Alondra-S-46 foram tolerantes a $2 \mathrm{mg} /$ litro de $\mathrm{Al}^{3+}$ na solução tratamento, porém exibiram sensibilidade quando se empregaram soluções com $4 \mathrm{mg} /$ litro de $\mathrm{Al}^{3+}$, sendo, portanto, considerados como moderädämentè sensiveis.

As linhagens IAC-103, IAC-105, IAC-107, IAC-108, IAC-110, IAC-112, IAC-113 e PAT-73121, tolerantes a $6 \mathrm{mg} / \mathrm{litro}$ de $\mathrm{Al}^{3+}$ nas soluções de tratamento, foram consideradas moderadamente tolerantes.

Os cultivares $\mathrm{BH}-1146$ e IAC-18, bem como as linhagens IAC-99, IAC-101, IAC-102, IAC-104 e IAC-109, apresentaram-se como tolerantes mesmo quando se adicionaram $10 \mathrm{mg} / \mathrm{litro}$ de $\mathrm{Al}^{3+}$ nas soluções de tratamento. 
QUADRO 4. Comprimento médio das raízes das linhagens e cultivares de trigo medido após 72 horas de crescimento na solução nutritiva completa, seguido a crescimento na solução de tratamento contendo seis diferentes concentraçōes de aluminio

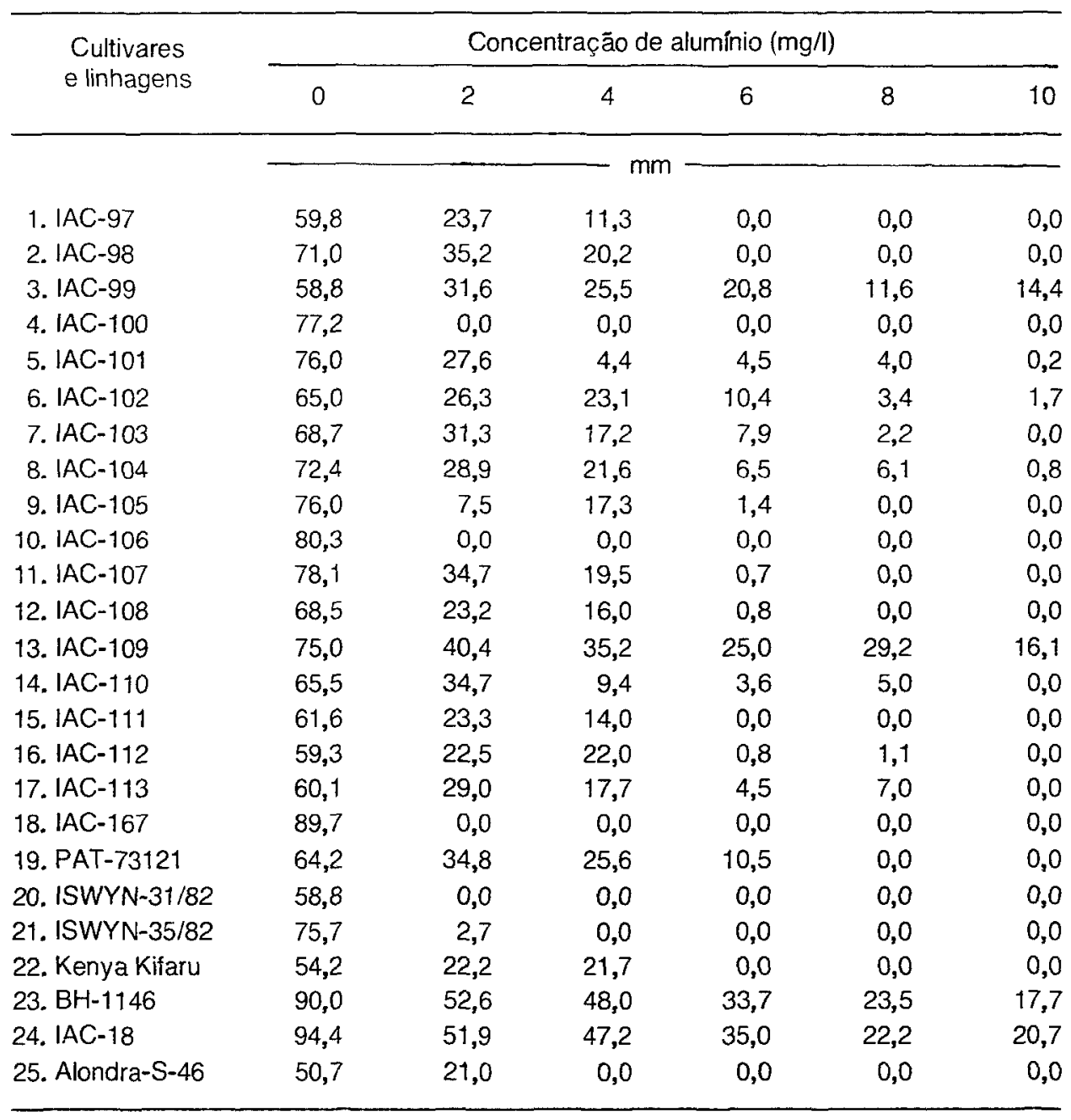

\section{CONCLUSÕES}

1) Considerando os diversos parâmetros analisados, salientaram-se as linhagens IAC-103, IAC-104, IAC-107, IAC-167 e PAT-73121, com boa produtividade, não diferindo estatisticamente, porém, dos cultivares controles $\mathrm{BH}-1146$, 
IAC-18 e Alondra-S-46, com resistência às ferrugens-do-colmo e da-folha em condição de campo (exceto IAC-103 e IAC-107), com ciclo precoce (excluindo (AC-167, que é de ciclo médio, e PAT-73121, de ciclo tardio), tolerantes a moderadamente tolerantes à toxicidade de $\mathrm{Al}^{3+}$ (exceto $\mid \mathrm{AC}-167$ ). A linhagem IAC-167, além da resistência às raças ocorrentes dos patógenos das ferrugens e do porte semi-anão, seria também uma fonte de maior número de grãos por espiga e maior fertilidade da espiga, isto é, maior número de grãos por espigueta. A linhagem IAC-100, que apresentou grãos mais pesados, também poderá ser utilizada no programa de melhoramento genético como fonte para elevar este componente de produção dos novos cultivares.

2) A linhagem IAC-167 e o cultivar Alondra-S-46 revelaram-se resistentes às oito raças testadas de ferrugem-do-colmo, em casa de vegetação e em condiçōes de campo. As linhagens IAC-103 e Kenya Kifaru foram resistentes a sete raças dessa ferrugem em casa de vegetação, porém o IAC-103 apresentou-se suscetivel em condições de campo.

3) Em casa de vegetação, a linhagem IAC-167 mostrou resistência a três raças de $P$. recondita, agente causal da ferrugem-da-folha. Em condiçōes de infecção natural em estádio de planta adulta, as linhagens IAC-100, IAC-101, IAC-111, IAC-167 e PAT-73121 apresentaram-se com menor grau de infecção dessa ferrugem.

4) Em condição de campo, as linhagens IAC-108 e ISWYN-31/82 destacaram-se quanto à resistência ao agente causal de oidio, e as linhagens IAC-110 e IAC-111, quanto à menor ocorrência de doenças nas folhas.

5) As linhagens IAC-104, IAC-107, IAC-111, IAC-167, ISWYN-31/82 e o cultivar Alondra-S-46 mostraram plantas significativamente mais baixas do que as dos cultivares IAC-18 e BH-1146.

6) As linhagens IAC-100, IAC-106, IAC-167 e ISWYN-31/82 foram sensiveis à toxicidade de $\mathrm{Al}^{3+}$. A ISWYN-35/82 e o 'Alondra-S-46', moderadamente sensiveis; IAC-103, IAC-105, IAC-107, IAC-108, IAC-110, IAC-112, IAC-113 e PAT-73121, moderadamente tolerantes, e os cultivares BH-1146 e IAC-18 e as linhagens IAC-99, IAC-101, IAC-102, IAC-104 e IAC-109, tolerantes.

\section{SUMMARY}

WHEAT BREEDING: XVI. EVALUATION OF NEW INBRED LINES FOR THE STATE OF SÃO PAULO, BRAZIL

Twenty two inbred lines obtained at the Instituto Agronomico, from the wheat breeding program plus the cultivars $\mathrm{BH}-1146, \mathrm{AC}-18$ and Alondra-S-46 were evaluated in field experiments carried out at Campinas Experimental Center, at Tietê and Capão Bonito Experimental Stations and at Santa 
inês Farm, Maracaí, State of São Paulo, Brazil, during the years of 1983, 1984 and 1985. Grain yield, plant height, number of days from emergence to flowering and from emergence to maturation, percentage of lodging, head lenght, number of grain per spike and per spikelet, number of spikelets, weight of 100 grains, and resistance to the powdery mildew and to the stem and leaf rust agents, were evaluated under field conditions. Tests of resistance to stem and leaf and to aluminum tolerance were also made, respectively, in greenhouse and in laboratory. In relation to grain yield the lines $1 \mathrm{AC}-103$, IAC-104, IAC-107, IAC-167 and PAT-73121 showed good performance, but they did not differ from the control cultivars, $\mathrm{BH}-1146, \mathrm{AC}-18$ and Alondra-S-46. The lines IAC-104, IAC-107, IAC-111, IAC-167, ISWYN-31/82 and Kenya Kifaru exhibited the semidwarf type when compared to the tall cultivars $\mathrm{BH}-1146$ and $\mid \mathrm{AC}-18$. In reiation to the powdery mildew disease, the lines IAC-108 and ISWYN-31/82 showed high resistance under field conditions. The line $\mid A C-167$ and the cultivar Alondra-S-46 were resistant to eight races and $I A C-103$ and Kenya Kifaru were resistant to seven races of $P$. graminis tritici, causal agent of stem rust under greenhouse conditions. The lines IAC-104, IAC-108, IAC-110, IAC-111, IAC-167, ISWYN-31/82 and Kenya Kifaru showed high resistance to stem rust under natural conditions of plant infection. The line IAC-167 was resistant to three races of $P$. recondita at the seedling stage under greenhouse conditions. The lines IAC-100, IAC-101, IAC-111, IAC-167 and PAT-73121 presented good resistance to this disease under natural infection out in the field. The lines IAC-99 and IAC-109 were as tolerant to the presence of $10 \mathrm{mg} / \mathrm{l}$ of $A \mathrm{I}^{3+}$ in the nutrient solution as the cultivars $\mathrm{IAC}-18$ and $\mathrm{BH}-1146$.

Index terms: wheat, cultivars, lines, grain yield, resistance, rusts, aluminum toxicity, semidwart.

\section{REFERÊNCIAS BIBLIOGRÁFICAS}

BARCELLOS, A.L. Ferrugem-da-folha de trigo - populaçāo patogênica no Brasil em 1983 e 1984, e reaçōes dos cultivares dos ensaios finais da Regiāo Centro-Sul. In:REUNIÃO DA COMISSĀO CENTRO-SUL-BRASILEIRA DE PESQUISA DE TRIGO, 1., Londrina, 1985. Passo Fundo, EMBRAPA, Centro Nacional de Pesquisa de Trigo, 1985. p.1-38.

CAMARGO, C.E.O. Estudos de variedades de trigo para o Estado de São Paulo. Piraciaba, Escola Superior de Agricultura "Luiz de Queiroz", 1972. 102p. Tese (Doutoramento)

; FELICIO, J.C.; BARROS, B.C.; FREITAS, J.G.; FERREIRA FILHO, A.W.P. \& CASTRO, J.L. Melhoramento do trigo: novas linhagens para o Estado de São Paulo. Arquivos do instituto Biológico, São Paulo, 52(1/4):27-37, 1985a.

trigo XV Produtividade, , São Paulo. Bragantia, Campinas, 46(1):105-120, 1987a. ; FREITAS, J.G.; BARROS, B.C.; CASTRO, J.L. \& SABINO, J.C. Melhoramento do trigo. XII. Comportamento de novas linhagens e cultivares no Estado de Sāo Paulo. Bragantia, Campinas, 44(2):669-685, 1985 b. 
CAMARGO, C.E.O; FELICIO, J.C. \& ROCHA JÚNIOR, L.S. Trigo: tolerância ao alumínio em solução nutritiva. Bragantia, Campinas, 46(2):183-190, $1987 \mathrm{~b}$.

\& ISSA, E. Estudo comparativo de cultivares de trigo em Latossolo Roxo no Vale do Paranapanema. Bragantia, Campinas, 33:75-86, 1974.

; KRONSTAD, W.E. \& METZGER, R.J. Parent-progeny regression estimates and associations of height level with aluminum toxicity and grain yield in wheat. Crop Science, 20:355-358, 1980.

\& OLIVEIRA, O.F. Tolerância de cultivares de trigo a diferentes níveis de alumínio em solução nutritiva e no solo. Bragantia, Campinas, 40:21-31, 1981.

COELHO, E.T. Informações sobre ferrugem-do-colmo do trigo (Puccinia graminis tritici). In:REUNIĀO CENTRO-SUL-BRASILEIRA DE PESQUISA DE TRIGO, 1., Londrina, 1985. Passo Fundo, EMBRAPA, Centro Nacional de Pesquisa do Trigo, 1985 . p.1-5.

FELÍCIO, J.C.; BARROS, B.C.; CAMARGO, C.E.O. \& BÄR, W.H. Maracal (IAC-17) e Xavantes (IAC-18): cultivares de trigo para o Estado de Sāo Paulo. Bragantia, Campinas, 42:15-25, 1983.

; CAMARGO, C.E.O.; BARROS, B.C.\& VITTI, P. Iguaçu (IAC-21) e Araguaia (IAC-22): cultivares de trigo de sequeiro para o Estado de São Paulo. Bragantia, Campinas, 44(1):115-128, 1985.

MEHTA, Y.R. Doenças do trigo e seu controle. São Paulo, Ceres, 1978. 190p.

MOORE, D.P.; KRONSTAD, W.E. \& METZGER, R.J. Screening wheat for aluminum tolerance. In: WORKSHOP ON PLANT ADAPTATIONS TO MINERAL STRESS IN PROBLEM SOILS, Beltsville, Maryland, 1976, edited by Madison J. Wright - Proceedings. Itaca, Cornell University, 1976. p.287-295. 